\title{
Recurrent Herpes Zoster as a Sign of HIV Infection
}

\author{
Fatma Etgu ${ }^{1(\mathbb{D})}$ \\ ${ }^{1}$ Department of Dermatology, Faculty of Medicine, Ordu University, Ordu, Turkey
}

Copyright@ Author(s) - Available online at https://dergipark.org.tr/en/pub/mbsjohs

Content of this journal is licensed under a Creative Commons Attribution-NonCommercial 4.0 International License,

\author{
Received: 05 November 2020, Accepted: 08 April 2021, Published online: 30 April 2021 \\ (C) Ordu University Institute of Health Sciences, Turkey, 2021
}

\begin{abstract}
Herpes Zoster is characterized with painful dermatomal blisters, which commonly seen in elderly or immuncompromised people. It is caused by varicella zoster virüs (VZV). HIV infection is known as a risk factor for herpes zoster and for developments of its complications. Cutaneous findings can be the presenting symptom for HIV infection. In the presence of HIV infection, $\mathrm{HZ}$ can be prolong or can complicate evet its recurrence rate increases. $\mathrm{HZ}$ recurrences are usually seen in immuncompromised individuals.

In the presence of HIV infection, the risk of $\mathrm{HZ}$ increases up to 12-17 fold. Prophylaxis with daily asiclovir decrease the risk of $\mathrm{HZ}$ by $68 \%$. Vaccination for $\mathrm{HZ}$ was found safe and effective in HIV patients with CD4+ cell count more than 200 cells/. Skin findings are frequent in HIV patients and its diversity change according to the stages of the disease. Here we report a case of recurrent $\mathrm{HZ}$ which later diagnosed with positive for $\mathrm{HIV}$, therefore, to mention HIV as a risk factor in cases of recurrent HZ.
\end{abstract}

Keywords: Herpes Zoster, recurrence, HIV, acylovir, shingles

Suggested Citation: Etgu F. Recurrent herpes zoster as a sign of HIV infection. Mid Blac Sea Journal of Health Sci, 2021; 7(1):150153.

\section{Address for correspondence/reprints:}

Fatma Etgu

Telephone number: $+90(533) 3673667$

E-mail: ftmyildirim@hotmail.com
Note: The study was presented as a poster at the 19th National Family Medicine Congress. 


\section{Introduction}

Herpes Zoster is characterised with painful dermatomal blisters, which commonly seen in elderly or immuncompromised people. It is caused by varicella zoster virüs (VZV) (1). The risk of HZ increase with the age. In case of immunodeficiencies, $\mathrm{HZ}$ recurrence risk increase $(1,2)$. HIV infection is known as a risk factor for herpes zoster, recurrences of $\mathrm{HZ}$ and for the developments of its complications $(2,3)$. It is well-known that HIV is associated with increased risk of mucocutaneous manifestations. Cutaneous findings can be the presenting symptom for HIV infection. Skin diseases can occur anytime in the course of the disease. (4). Prevelance of mucocutaneous disease in HIV- infected indivudials can increase up to $90 \%$ (5). With highly active antiretroviral trerapy (HAART), survival of HIVinfected patients prolonged, resultantly, they faced more dermatological findings. The immune status of the individual and the use of HAART, are the main factors determining the mucocutaneous manifestations of HIV infection. IN HIV-infected induviduals, the skin diseases which can be also be seen in otherwise healthy populations, usually have more protracted course, they may have more severe course, they can be resistant to the treatments, besides they can recur and have atypical presentations and courses. Mucocutaneous manifestations help both in the diagnosis and staging of the disease in HIV positive individuals $(4,5)$. Dermatologist should be aware of mucocutaneous findings of HIV infections and should not be late to investigate the patient for the HIV infection when necassary. Here we report a case of recurrent $\mathrm{HZ}$ which later diagnosed with positive for HIV, therefore, to mention HIV as a risk factor in cases of recurrent $\mathrm{HZ}$.

\section{Case}

49 years old male patient applied to the dermatology clinic with the painful blisters on the back and umbilical area. In dermatologic examination, there were multiple vesicles located on the erythematous base, beginning from the middle of the back towards to the umbilicus. Vesicles are grouped together and distrubuted dermatomally. Tzanck test was performed and there were multinucleated giant cells and acantholytic cells. VZV IgG was positive. After the dermatological examination and the tests performed the patient was diagnosed with HZ. Valacyclovir $1000 \mathrm{mg}$ three times daily for 7 days prescribed to the patient. After at the end of the first week of the treatment the patient reevaluated. The lesions were crusted (figure 1 and 2 ), but the patient still had severe pain. When we asked patient in detail the patient did not describe any stres or anxiety. The patient informed us about he had similar lesions and diagnosed with $\mathrm{HZ}$ six months ago. Because of the young age of the patient and the recurrence of $\mathrm{HZ}$ we did detailed physical examination to find out any underlying immundeficiency. The patient did not have any fever, weight loss, night sweats. He had no known any medical illness and he was not on any treatment. In physicaml examination there were no lympadenopath. Routine biochemistry, complete blood counts, viral hepatitis serology, sedimentationn level and C-reactive peptide level were within normal range but the patient was found positive for anti-HIV. The patient was consulted to the infectios diseases department. Informed consent of the patient taken prior to the publication.

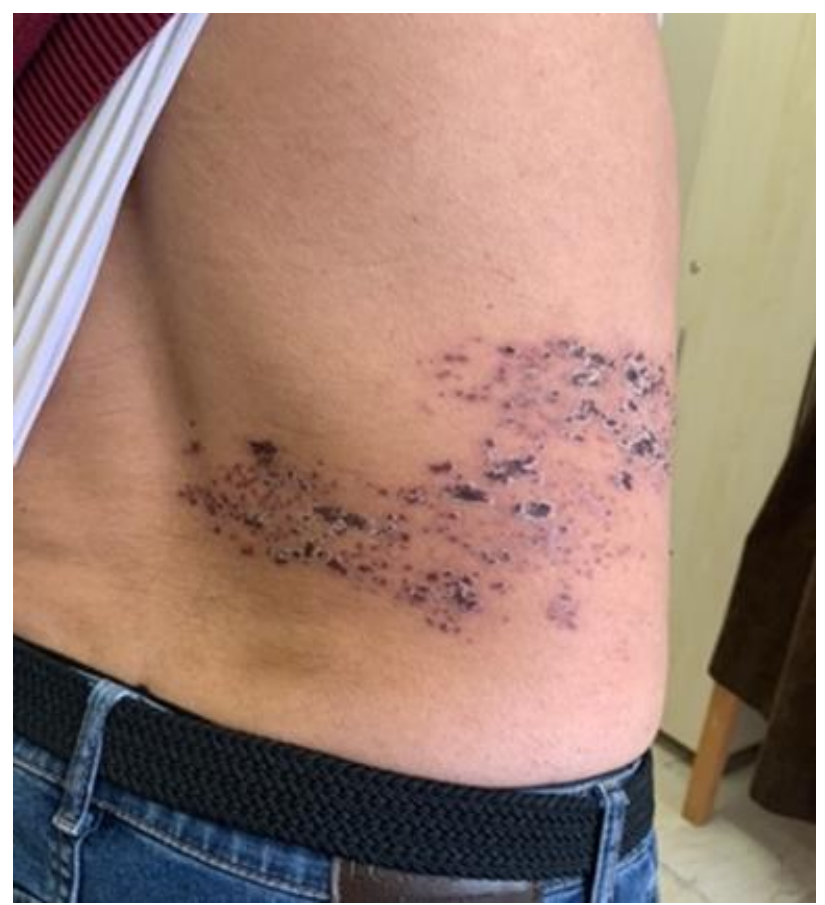

Figure 1 After 1 week of treatment, dermatomally located necrotik crust and erosions (dorsal) 


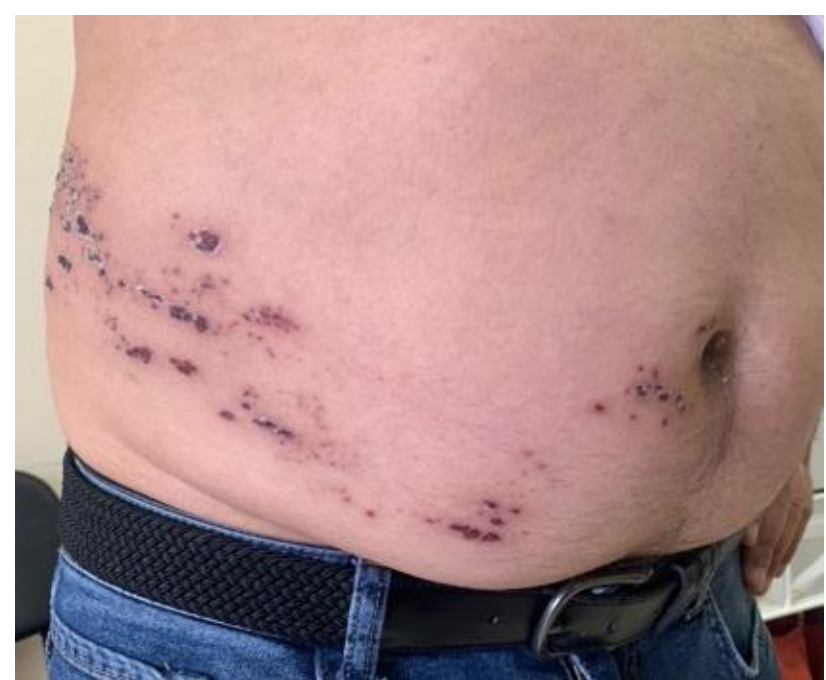

Figure 1 After 1 week of treatment, dermatomally located necrotik crust and erosions (abdominal)

\section{Discussion}

$\mathrm{HZ}$ is the result of reactivation of latent VZV in the dorsal root ganglia which ususally caused varicella during childhood period. $\mathrm{HZ}$ is characterised with dermatomally distrubuted painful vesicles. The overall risk of $\mathrm{HZ}$ was reported $20-30 \%$ and its prevelance significantly increases after the age of 50 . Even the risk reach up to $50 \%$ after 85 years old $(1,3)$. Also HZ risk increases in the presesnce of immundeficiency (6).

It is accepted that people get HZ usually once in their life. when it recurs it is thought as the sign of immunodeficiency. The recurrence rate for HZ vary between $0,2 \%-12,5 \%$ in the studies. The difference between the studies can be because of study, population and total time that patients followed $(7,8)$. Besides age and immunodeficiency the risk of recurrence of $\mathrm{HZ}$ increases with chronic diseases as diabetes, hypertension, dyslipidemia, chronic obstructive lung disease, depression and hypothyroidism. In addition the people who have more serious first epizode and whose pain lasts more than 30 days have more pronounced risk of $\mathrm{HZ}$ recurrence (9).

In the presence of HIV infection the risk of $\mathrm{HZ}$ increases up to $12-17$ fold. HIV positive patients usually have more complicated disease, the disease can spread more than one dermatome, it has more complication such as postherpetic nevralgia and they have more recurrence risk $(3,7,8)$. Lee et al. reported that $\mathrm{HZ}$ can be sign of HIV infection especially at young individuals (10). In their study Barnabas et al. showed that acylovir prophylaxis reduced $\mathrm{HZ}$ events in HIV-infected individuals. But acylovir prophylaxis did not prevent $\mathrm{HZ}$ recurrence among persons who reported previous history of HZ. HZ vaccine recommended people after age 60 , but in the case of immunosupression it is contraindicated, such as HIVinfected individuals with CD4+ cell count less than 200 cell / $\mu \mathrm{L}$ (11).

Skin findings are frequent in HIV patients and its diversity change according to the stages of the disease. As a consequence skin findings can be clue for the stage of the infection $(4,5)$. Although with administration of the antiretroviral treatment (ART) the frequency of opportunistic decreased, the risk of $\mathrm{HZ}$ remained same. On the contrary some studies reported as the frequency of $\mathrm{HZ}$ declined after ART (3). Herpes Zoster, along with extensive oral candidiasis, and oral hairy leukoplakia, as indicator of the acquired immunodeficiency syndrome (AIDS) (12).

$\mathrm{HZ}$ which is mild and confined to only one dermatomal region can be treated with asiclovir, valasiclovir and famciclovir in HIV-infected patients. In patients with more complicated, disseminated and severe cases, opthalmic HZ and Ramsey Hunt syndrome should be treated with intravenous asiclovir. Although the asiclovir prophylaxis decreses the prevelance of $\mathrm{HZ}$ in $\mathrm{HIV}+$ patients, prolonged use is not recomended (13).

\section{Conclusion}

As a global health issue, HIV has a wide list of cutaneous manifestations, some of which can help in the diagnosis of HIV infection. It is known as the frequency of $\mathrm{HZ}$ increases steadily with age and in the presence of immunsupression. And it is also known that recurrences of $\mathrm{HZ}$ usually ocur in patients who have immun supression for various cause As a consequence in young patients, patients with protracted or severe disease, $\mathrm{HZ}$ resistant to treatment, and also recureent diseases should raise suspicion for underlying immunsupression and HIV should be kept in mind.

Herpes Zoster, Recurrence, HIV, acylovir, shingles

The authors have no conflict of interest to declare

"The author received no specific funding for this work." 


\section{Patient Approval}

Approval was received for this study from the patient. Peer-review: Externally peer-reviewed.

Author Contributions: Concept, Design, Literature search, Data Collection and Processing, Analysis or Interpretation, Writing: F.E.

Conflict of Interest: No conflict of interest was declared by the author.

Financial Disclosure: The author declared that this study hasn't received no financial support.

\section{References}

1. Yanni EA, Ferreira G, Guennec M, El Hahi Y, El Ghachi A, Haguinet F, et al. Burden of herpes zoster in 16 selected immunocompromised populations in England: a cohort study in the Clinical Practice Research Datalink 2000-2012. BMJ Open. 2018;7;8(6): e020528.

2. Da Silva AMPS, De Moraes-Pinto MI, Succi RCM, Terreri MT, Machado DM. Clinical and Laboratory Characteristics of Herpes Zoster in Patients With HIV/AIDS and Those With Juvenile Systemic Lupus Erythematosus. Pediatr Infect Dis J. 2020;39(7):624-627.

3. Jansen K, Haastert B, Michalik C, Guignard A, Esser S, Dupke S, et al. Incidence and risk factors of herpes zoster among hiv-positive patients in the german competence network for HIV/AIDS (KompNet): a cohort study analysis. BMC Infect Dis. 2013;10;13:372.

4. Karadag AS, Elmas OF, Altunay IK. Cutaneous manifestations associated with HIV infections: A great imitator. Clin Dermatol. 2020;38(2):160175.

5. Claasens S, Kannenberg S, Jordaan H. F, Moxley K, Smith R, de Wet J, \& Visser W. I. The prevalence and spectrum of mucocutaneous disease in South African people living with HIV and accessing care at a district-level hospital. Southern African journal of HIV medicine,2020; 21(1), 1154.

6. Kawai K, Gebremeskel BG, Acosta CJ. Systematic review of incidence and complications of herpes zoster: towards a global perspective. BMJ Open. 2014;10;4(6):e004833.

7. John AR, Canaday DH. Herpes Zoster in the Older Adult. Infect Dis Clin North Am, 2017;;31(4):811-826.

8. Kim YJ, Lee CN, Lee MS, Lee JH, Lee JY, Han K, et al. Recurrence Rate of Herpes Zoster and Its Risk Factors: a Population-based Cohort Study. J Korean Med Sci. 2018;20;34(2):e1
9. Yawn BP, Wollan PC, Kurland MJ, St Sauver JL, Saddier P. Herpes zoster recurrences more frequent than previously reported. Mayo Clin Proc. 2011;86(2):88-93.

10.Lee Y-T, Nfor ON, Tantoh DM, Huang J-Y, Ku W-Y, Hsu S-Y, et al. Herpes Zoster as a Predictor of HIV Infection in Taiwan: A Population- Based Study. PLoS ONE, 2015;10(11): e0142254.

11.Barnabas RV, Baeten JM, Lingappa JR, Thomas KK, Hughes JP, Mugo NR, et al. Partners in Prevention HSV/HIV Transmission Study Team. Acyclovir Prophylaxis Reduces the Incidence of Herpes Zoster Among HIV-Infected Individuals: Results of a Randomized Clinical Trial. J Infect Dis. 2016;213(4):551-5.

12.Draganescu M, Baroiu L, Iancu A, Dumitru C, Radaschin D, Polea E. D, et al. Perspectives on skin disorder diagnosis among people living with HIV in southeastern Romania. Experimental and therapeutic medicine, 2021;21(1), 97.

13.Lewis DJ, Schlichte MJ, Dao H Jr. Atypical disseminated herpes zoster: management guidelines in immunocompromised patients. Cutis. 2017 ;100(5):321;324;330. 